\title{
BMJ Global Health Boys are more likely to be undernourished than girls: a systematic review and meta-analysis of sex differences in undernutrition
}

\author{
Susan Thurstans (D) , ${ }^{1}$ Charles Opondo (D) , ${ }^{2,3}$ Andrew Seal (D) , ${ }^{4}$ \\ Jonathan Wells (D) , ${ }^{5}$ Tanya Khara, ${ }^{6}$ Carmel Dolan, ${ }^{6}$ André Briend, ${ }^{7,8}$ Mark Myatt, ${ }^{9}$ \\ Michel Garenne (D) , ${ }^{10,11,12,13}$ Rebecca Sear (D) , ${ }^{1}$ Marko Kerac (D) ${ }^{1,14}$
}

To cite: Thurstans S, Opondo C Seal $\mathrm{A}$, et al. Boys are more likely to be undernourished than girls: a systematic review and meta-analysis of sex differences in undernutrition. BMJ Global Health 2020;5:e004030. doi:10.1136/ bmjgh-2020-004030

Handling editor Seye Abimbola

Received 23 September 2020 Revised 6 October 2020 Accepted 9 October 2020

Check for updates

(C) Author(s) (or their employer(s)) 2020. Re-use permitted under CC BY. Published by BMJ.

For numbered affiliations see end of article.

Correspondence to

Susan Thurstans;

susan.thurstans@|shtm.ac.uk

\section{ABSTRACT}

Background Excess male morbidity and mortality is well recognised in neonatal medicine and infant health. In contrast, within global nutrition, it is commonly assumed that girls are more at risk of experiencing undernutrition. We aimed to explore evidence for any male/female differences in child undernutrition using anthropometric case definitions and the reasons for differences observed. Methods We searched: Medline, Embase, Global health, Popline and Cochrane databases with no time limits applied. Eligible studies focused on children aged 0-59 months affected by undernutrition where sex was reported. In the meta-analysis, undernutrition-specific estimates were examined separately for wasting, stunting and underweight using a random-effects model.

Results 74 studies were identified: 44/74 studies were included in the meta-analysis. In 20 which examined wasting, boys had higher odds of being wasted than girls (pooled OR $1.26,95 \% \mathrm{Cl} 1.13$ to 1.40). 38 examined stunting: boys had higher odds of stunting than girls (pooled OR 1.29 95\% $\mathrm{Cl} 1.22$ to 1.37). 23 explored underweight: boys had higher odds of being underweight than girls (pooled OR 1.14, 95\% $\mathrm{Cl} 1.02$ to 1.26). There was some limited evidence that the female advantage, indicated by a lower risk of stunting and underweight, was weaker in South Asia than other parts of the world. 43/74 (58\%) studies discussed possible reasons for boy/girl differences; 10/74 (14\%) cited studies with similar findings with no further discussion; $21 / 74(28 \%)$ had no sex difference discussion. 6/43 studies (14\%) postulated biological causes, 21/43 (49\%) social causes and 16/43 $(37 \%)$ to a combination.

Conclusion Our review indicates that undernutrition in children under 5 is more likely to affect boys than girls, though the magnitude of these differences varies and is more pronounced in some contexts than others. Future research should further explore reasons for these differences and implications for nutrition policy and practice.

\section{INTRODUCTION}

Undernutrition is a serious public health problem affecting millions of children worldwide. Recent estimates indicate that stunting

\section{Key questions}

What is already known?

- Undernutrition (wasting, stunting and underweight) is a public health problem affecting millions of children aged under 5 years globally.

- Although higher neonatal and infant morbidity/mortality for boys is well described, little attention has been given to sex differences in the field of undernutrition due to an assumption that girls are very often disadvantaged over boys.

What are the new findings?

- In most settings studied, undernutrition is more common among boys than girls, though the extent of these differences varies and is reversed in a few contexts.

- Both biological and social mechanisms have been proposed to be responsible for the observed differences as well as a combination of the two.

(low height-for-age) affects approximately 149 million children, with consequences for growth and cognitive development. Wasting (low weight-for-length), a life-threatening consequence of acute nutrient deficits and/or disease affects over 49 million children globally; 17 million of whom are severely wasted. ${ }^{1}$ However, these numbers are based on prevalence estimates meaning true numbers may be considerably higher when incidence is taken into consideration. ${ }^{2}$

Sex (referring to biological attributes) and gender (referring to socially constructed roles, behaviours and identities) ${ }^{3}$ are important considerations in the public health domain and receive different prominence in different academic and professional fields. Despite considerable research on childhood sex differences in neonatal and infant health, different disciplines often hold surprisingly 


\section{Key questions}

What do the new findings imply?

- Greater awareness of actual sex differences is needed within the field of nutrition.

- While sex-specific data are routinely analysed and reported in nutrition surveys, it should be used in nutrition programming to better identify and understand what differences exist. Analysis should assess if the sex balance in programme admissions is reflective of the population undernutrition burden.

- Further research is needed to understand both the mechanisms behind and the reasons for that lead to sex and gender differences in undernutrition and their implications for nutrition policy and practice. Better epidemiological understanding is a priority, as is work to explore their consequent effects on morbidity and mortality.

contrary views on the relative vulnerability of male and female children.

In neonatal medicine and infant health communities, excess male morbidity and mortality is almost universally reported and is widely recognised. ${ }^{45}$ Boys are known to be more vulnerable than girls, from as early as the point of conception. ${ }^{6}$ Conditions common in childhood such as lower respiratory infections, diarrhoeal diseases, malaria and preterm birth are all more common in boys than girls, with the exception of measles, whooping cough and tuberculosis. ${ }^{7}$ All of these are not only causes of death but also of weight loss, growth faltering or severe undernutrition among young children. ${ }^{8}$ Boy-girl differences have not been explored in detail within the nutrition field, but girls are often widely viewed as more disadvantaged and vulnerable $^{9}$ from a gender perspective. ${ }^{10-13}$

How underlying biological mechanisms related to sex and social differences in gender translate into the risk of anthropometric deficits and related morbidity and mortality in the field of nutrition remains understudied. Likewise, the practical implications of these differences remain to be determined. In terms of growth and nutrition status, sex differences have long been recognised and reflected through growth charts targeted at individual sexes. ${ }^{1415}$ On average, boys are slightly heavier and longer at birth and throughout infancy compared with girls, and more detailed studies have shown that the extra average weight of boys is primarily lean mass, whereas fat mass is more similar between the sexes. ${ }^{16} 17$ To evaluate growth and nutritional status therefore, raw anthropometric data are conventionally converted to indices (eg, weight-for-age; weight-for-length, length-for-age) and expressed in comparison to reference populations as z-scores (SD scores, whereby +1 and -1 z-scores are one SD above and below the reference population median, respectively). Data published by WHO in 2006 represent a 'gold standard' of how children should grow and were developed from a globally representative reference population of healthy, breastfed children. In constructing the growth standards, data for boys and girls were analysed separately ${ }^{15}$ and the resulting growth charts should already therefore account for any sex differences. What has received little attention to date is whether sex differences reappear when z-scores are shifted away from the healthy reference range, which would indicate sex differences in susceptibility to undernutrition.

The objectives of this review were to systematically review the evidence for sex differences in undernutrition in children aged under 5 years, to explore evidence of any male/female differences in child undernutrition, and to document reasons given for any observed differences.

\section{METHODS}

This systematic review was conducted following the Preferred Reporting Items for Systematic reviews and Meta-Analyses (PRISMA) guidelines. ${ }^{18}$ A protocol for the review was defined, including inclusion and exclusion criteria, and was shared among authors for consensus. The protocol was then registered with the PROSPERO International prospective register of systematic reviews (CRD42018094818). The scope of this initial protocol was broad but as the review progressed and the heterogeneity of identified studies became increasingly apparent, we made a decision to divide our work into two parts: the first (this study) focuses on prevalence and recognition of sex-related differences; and the second, which will focus on the physiological and sociological mechanisms that may account for any identified differences.

\section{Search strategy}

Our search strategy captured the concepts of undernutrition, sex and gender. Detailed search terms are in box 1 .

Studies were identified by searching the Medline database using the above terms which were then adapted to Embase, Global health, Popline and Cochrane databases. No limits were applied for year of publication in order to capture historical publications on the subject. Studies were restricted to those that included terms for boy, girl, male, female, gender, or sex in the title or abstract, with the aim of filtering through the large body of literature that exists for undernutrition and capturing studies which either directly focused on sex and/or gender in the context of undernutrition or those which disaggregated and reported on it within main findings. As per the PRISMA recommendations, the search strategy was peer reviewed by a librarian.

\section{Eligibility criteria}

Studies were included in the review if they met the following criteria: human studies, age range of 0-59 months, male and female participants, outcomes related to the prevalence or determinants of undernutrition, and related morbidity and mortality. Studies were eligible for inclusion in the meta-analysis if they presented data disaggregated by sex for both the overall sample and the outcome of interest (wasting, stunting, underweight), or relevant ORs. Studies of children over 59 months, non-English language, animal studies and studies on overweight/obesity and micronutrient deficiencies were excluded. Both peer-reviewed and grey literature were 


\section{Box 1 Search terms}

1. undernutrition.mp. (5708)

2. malnutrition.mp. (39279)

3. malnutrition/ or exp fetal nutrition disorders/ or exp refeeding syndrome/ or exp severe acute malnutrition/ or exp kwashiorkor/ or exp starvation/ or exp wasting syndrome/ (25202)

4. (severe adj2 malnutrition).mp. (2131)

5. stunting.mp. (3456)

6. exp Growth Disorders/ (30538)

7. chronic malnutrition.mp. (519)

8. stunt*.mp. (6655)

9. MUAC.mp. (407)

10. mid upper arm circumference.mp. (771)

11. exp Nutritional Status/ (38539)

12. marasmus.mp. or Protein-Energy Malnutrition/ (7366)

13. famine.mp. (1726)

14. exp Starvation/ (9562)

15. (failure adj2 thrive).mp. (5307)

16. 1 or 2 or 3 or 4 or 5 or 6 or 7 or 8 or 9 or 10 or 11 or 12 or 13 or 14 or 15 (123406)

17. limit 16 to ("all infant (birth to 23 months)" or "newborn infant (birth to 1 month)" or "infant (1 to 23 months)" or "preschool child (2 to 5 years)") (35919)

18. (boy* or girl* or male* or female* or gender or sex).ti,ab. (177252)

19. 17 and 18 (6631)

Numbers in parenthesis show the number of search results for each line.

selected. In studies that included data for children both under and over 59 months, where possible, we extracted the data for children $<59$ months only. Where this was not possible, studies were excluded.

\section{Data extraction}

All records identified through the search were imported into EndNote (EndNote V.X8, Clarivate Analytics). Duplicates were identified and removed. Initial screening was conducted by reading titles and abstracts to identify and remove studies which clearly did not fit our scope. Detailed review of the full text of all remaining results was conducted to determine which met the inclusion and exclusion criteria. When it was not clear how to classify an article, this was resolved through discussion and consensus with two or more authors.

A data extraction template was piloted on a small number of articles before being finalised. Data were extracted on study characteristics and outcomes of interest. These included aims and types of studies, sample size, prevalence and male/female ORs for undernutrition, and explanations offered for any differences identified.

\section{Analysis}

Due to variations in type of paper and study design, the analysis was conducted in two parts: a qualitative systematic review followed by a meta-analysis. We performed random-effects meta-analyses to pool estimates from studies that included a measurement of undernutrition prevalence, or which assessed risks and determinants of undernutrition, and stratified results by sex. Missing counts, denominators and effect estimates such as ORs, relative risk and their associated CIs were calculated from other information provided where it was possible to do so. Studies that presented only adjusted ORs or risk ratios were excluded given that studies were likely to adjust for different factors and such adjusted effect estimates were not directly comparable. Undernutrition-specific estimates were pooled separately for wasting, stunting and underweight using a random-effects model. Analysis was also stratified by age and country. Pooled effects are presented as ORs and 95\% CIs. Meta-regression was conducted to assess whether study-specific factors could explain the heterogeneity of effect estimates across studies. Statistical analysis was conducted using Stata V.15.1 (StataCorp 2017, Stata Statistical Software, College Station, Texas, USA).

In all studies conducted earlier than 2006, the National Center for Health Statistics (NCHS) growth ${ }^{19}$ references had been used. In all post-2006 studies that were included, the WHO (2006) growth standards for wasting, stunting and underweight, as measured through SD from the mean z-scores, were used. Wasting was defined by weight-for-height z-score $<-2$; stunting was defined by height-for-age $z$-score $<-2$; underweight was defined by weight-for-age $\mathrm{z}$-score $<-2$.

\section{Risk of bias assessment}

We adapted the National Heart, Lung and Blood institute study quality assessment tools for Observational cohort and cross-sectional studies to assess the quality of studies, ${ }^{20}$ and applied it to studies identified for the meta-analysis. Using this tool, we assessed data sources, a study's presentation of aims and objectives and target populations, the appropriateness of anthropometric methods and the presentation of results. We adapted the tool to assess if studies acknowledged sex differences in the discussion of results.

\section{Patient and public involvement}

The design of this review meant it was not appropriate or possible to involve patients or the public in the design, or conduct, or reporting, or dissemination plans of our research.

\section{RESULTS \\ Study selection}

The study flow chart in figure 1 summarises our process of identifying studies. The final search of Embase, Global health, Popline and Cochrane databases conducted in March 2020 identified 34270 studies, including both peer-reviewed studies and grey literature. In addition, 21 studies were found from other sources. After removing duplicates, 22 357 studies remained. Initial screening excluded 21 925 studies as they were unrelated to our review questions. Full texts of the 432 remaining studies were reviewed in detail to assess eligibility. At this stage, a further 358 studies were discarded as they did not meet the inclusion criteria, mostly because there was no mention of sex or gender in relation to undernutrition. Seventy-four studies were therefore included 


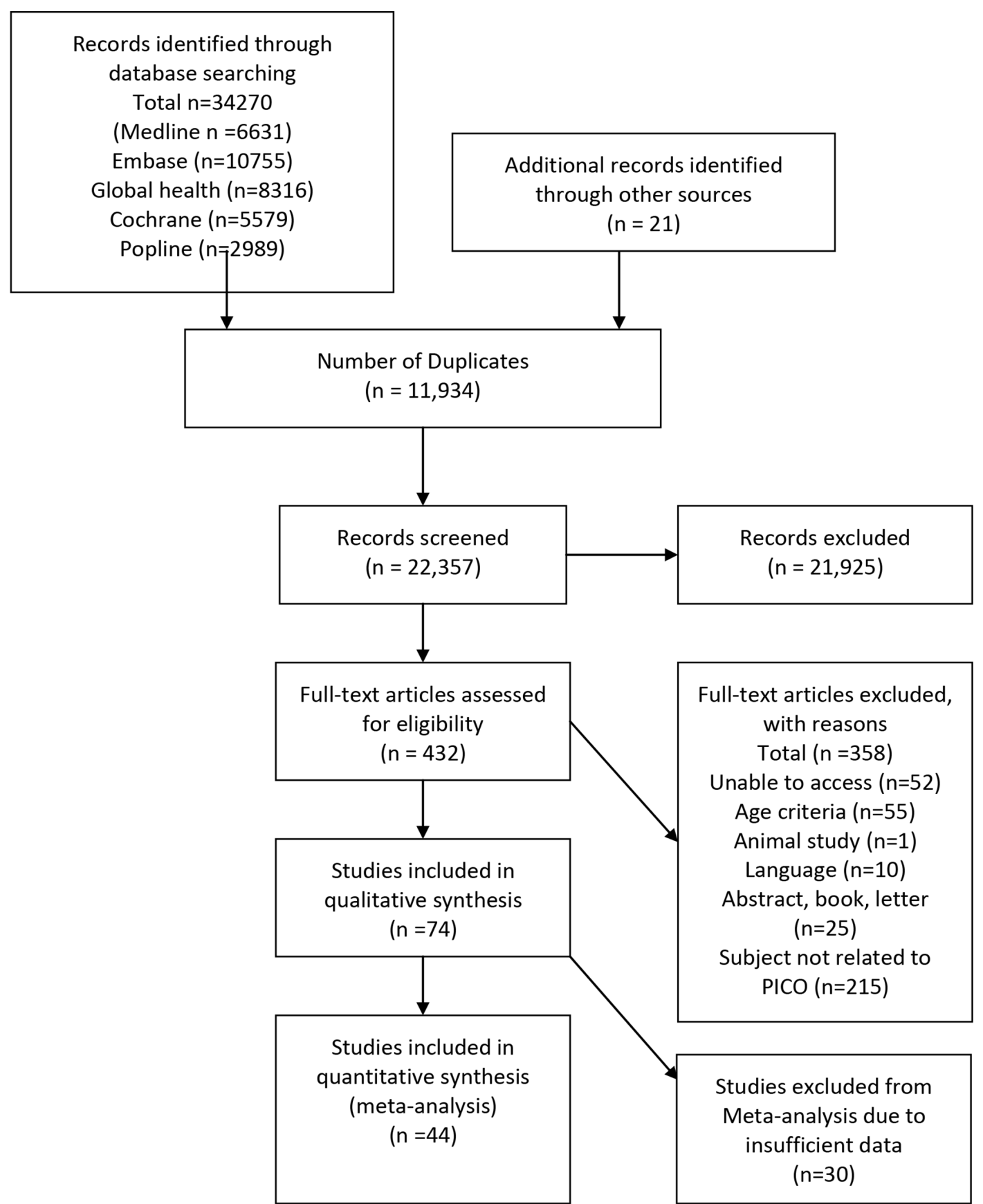

Figure 1 PRISMA flow diagram. PICO, Population, Intervention, Comparison, Outcome; PRISMA, Preferred Reporting Items for Systematic reviews and Meta-Analyses.

in the qualitative synthesis. Finally, we reviewed the 74 studies for inclusion in the meta-analysis and excluded 30 on the basis of insufficiently disaggregated data (which prevented the calculation of ORs). Thus, 44 studies were included in the meta-analysis.

\section{Study characteristics}

Table 1 shows the characteristics of each of the studies included in the review. The studies selected for the review varied widely in terms of aims and study design. Many were observational, assessing prevalence of undernutrition and related risk factors and many included secondary data analysis. The outcomes, both primary and secondary, also varied widely. The studies took place in more than 30 countries (some covered multiple countries). The studies were spread across Central Africa (3/74) East Africa $(33 / 74)$, East Asia $(1 / 74)$, North Africa $(1 / 74)$, Oceania $(1 / 74)$, South America $(2 / 74)$, South Asia $(10 / 74)$, South East Asia $(9 / 74)$, South West Pacific $(1 / 74)$, West Africa $(8 / 74)$ and multiple countries $(5 / 74)$.

Where sample size was clearly stated, the included studies involved 3361736 participants. Distribution of boys and girls was not provided for all studies but, where they were, results showed a total of 1489586 $(44.3 \%)$ girls and $1531859(45.6 \%)$ boys. Inclusion 
un

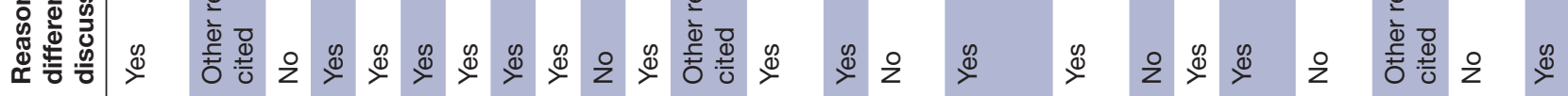

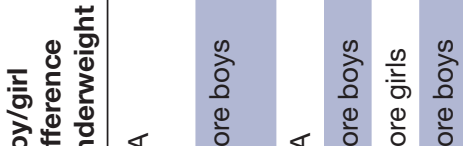

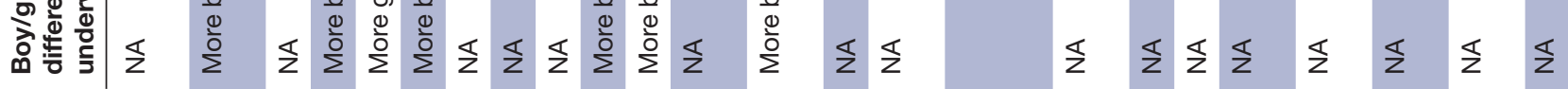

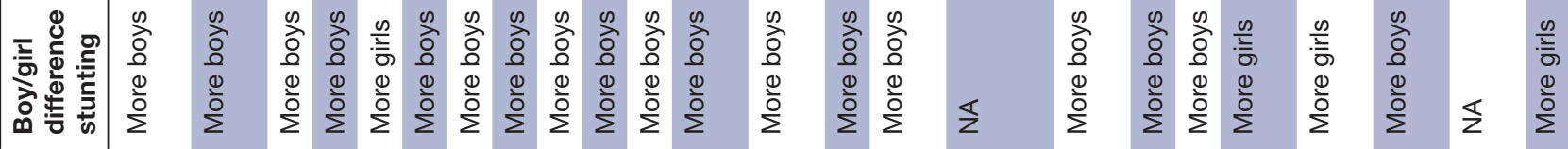

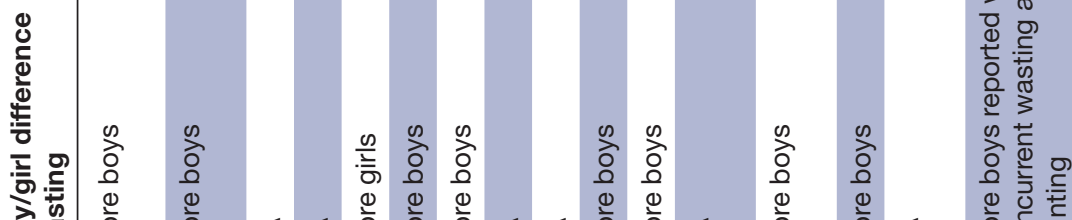

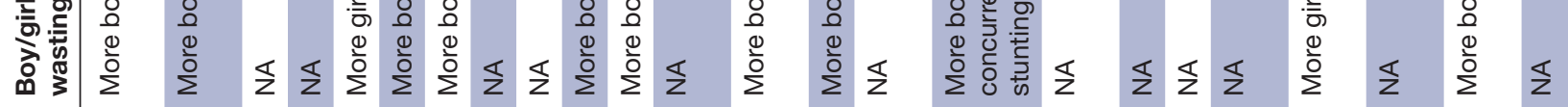

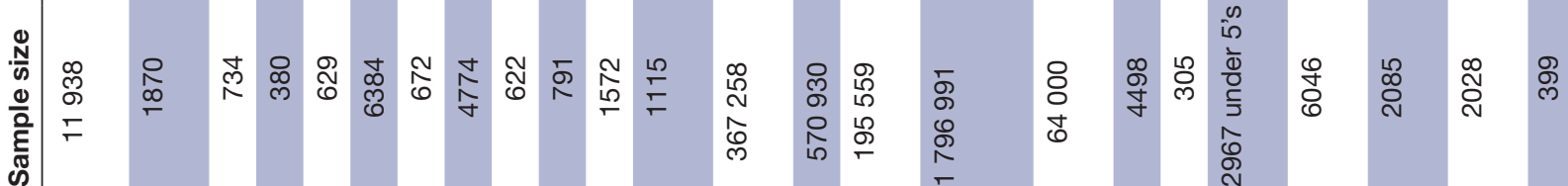

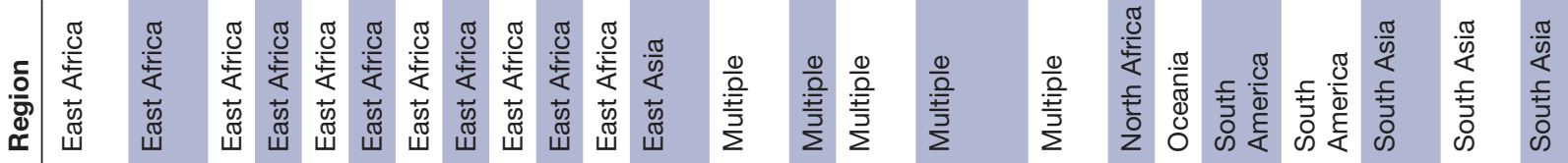

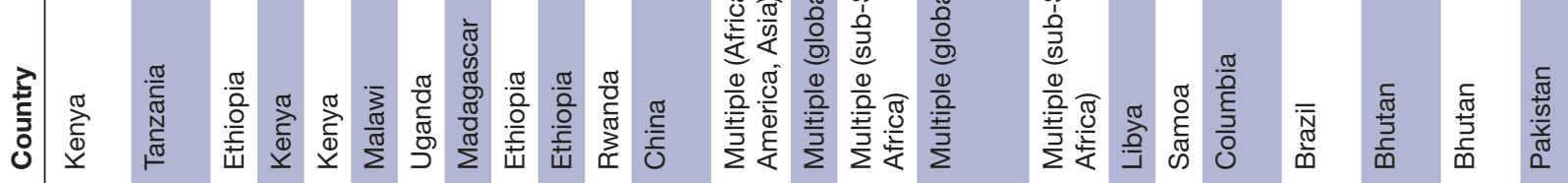

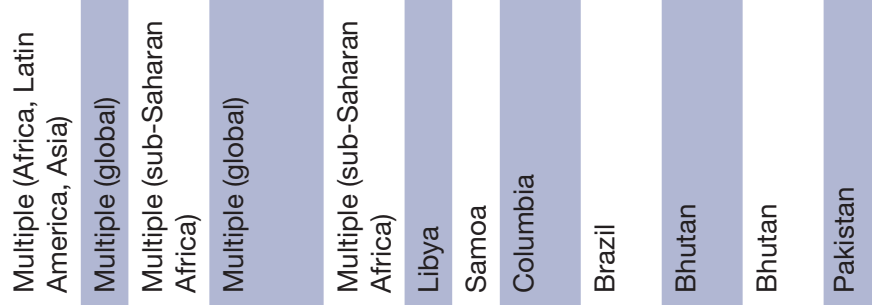

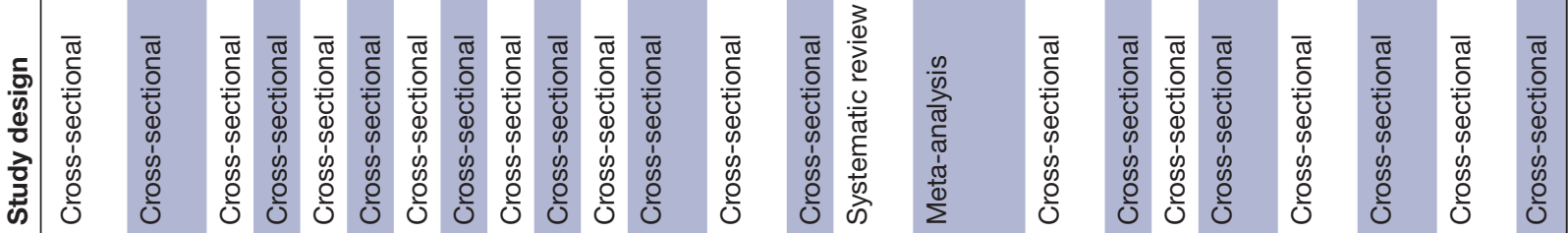

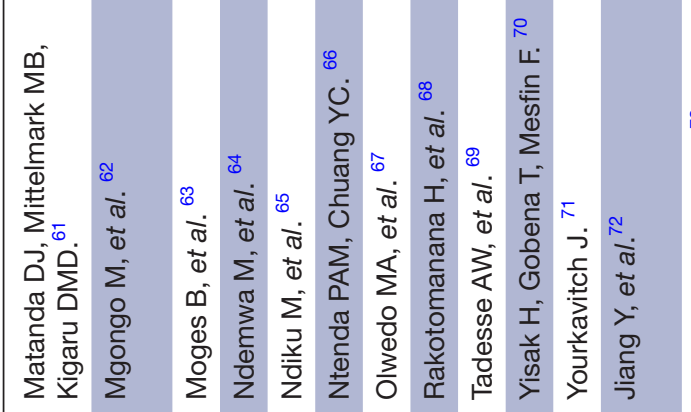

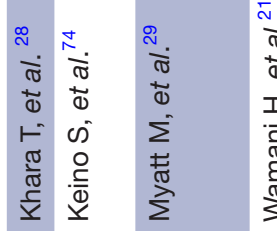

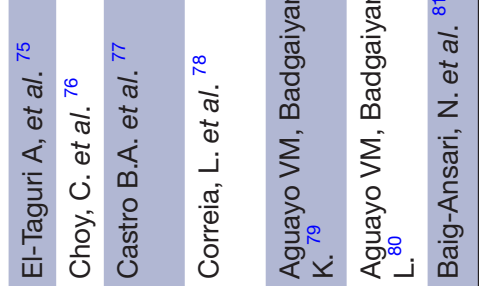




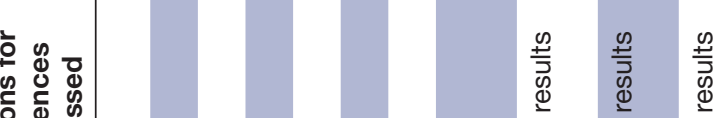

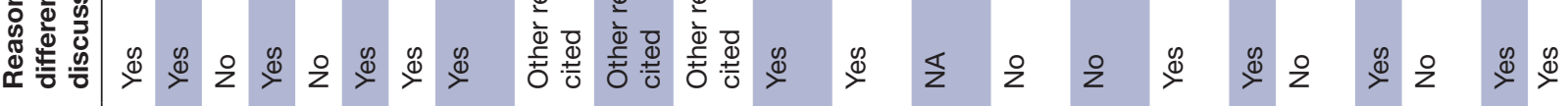

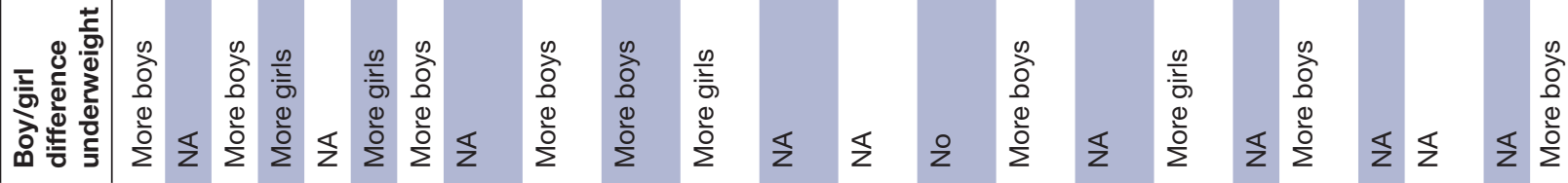

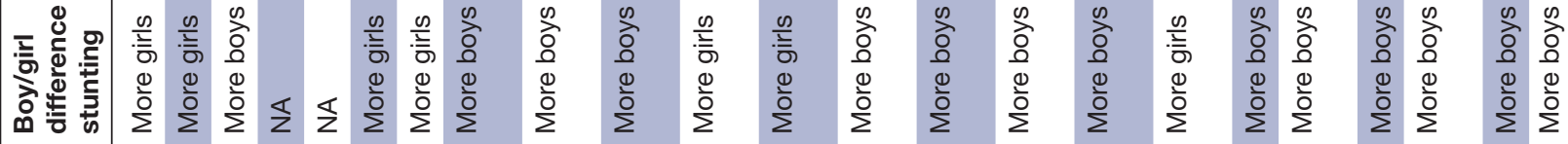

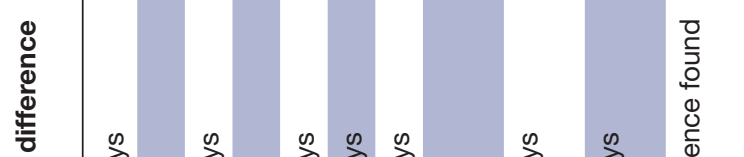

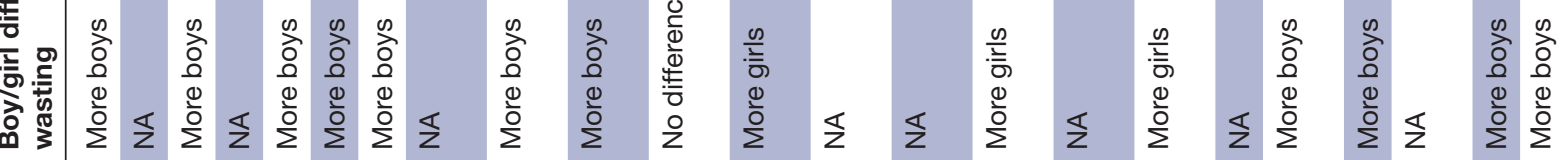

$\frac{n}{2}-0$ t

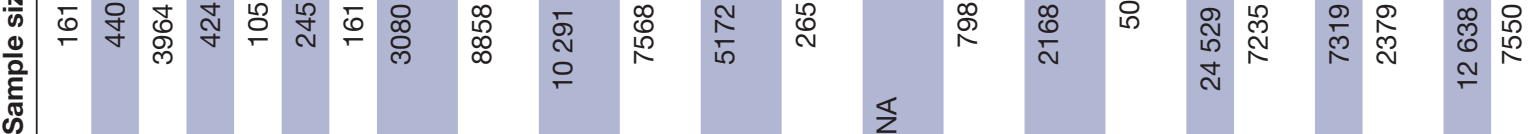

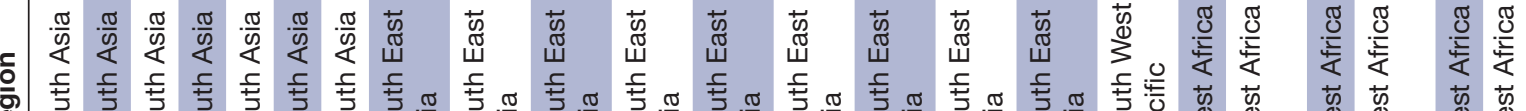

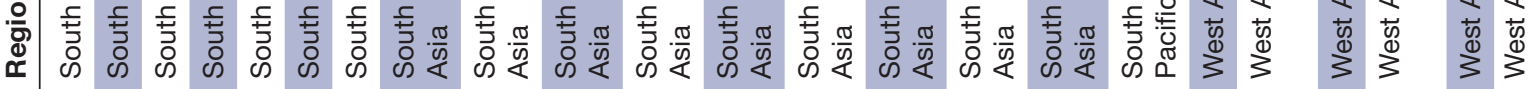

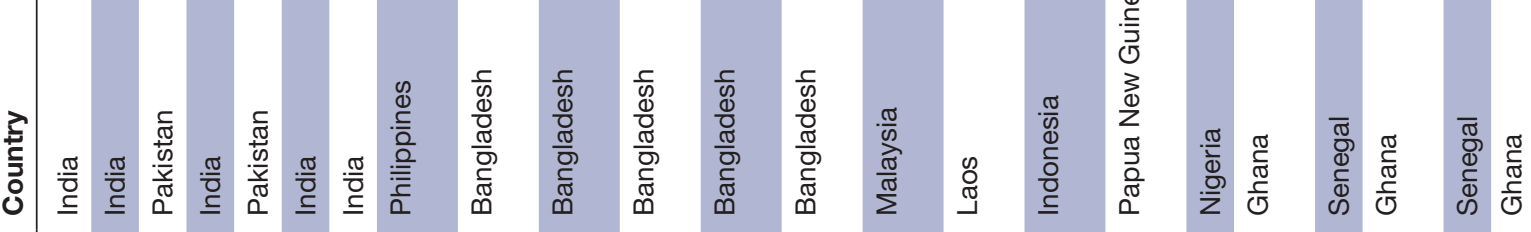

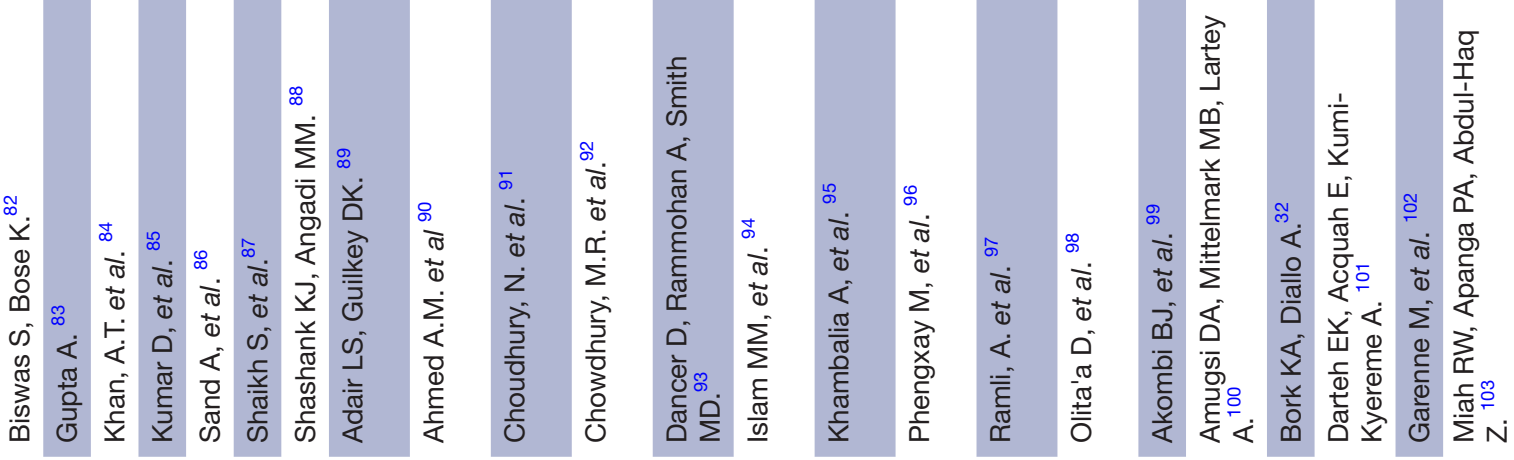


criteria for age entailed a mix of studies covering all children aged 0-59 months with others focused on subsets of these children.

\section{Meta-analysis}

We identified 74 studies that had measured undernutrition in the form of wasting, stunting and underweight and reviewed them for inclusion in the meta-analysis. Forty-four studies included extractable data, fully disaggregated by sex and were therefore eligible for inclusion, 41 of these were cross-sectional and 3 were longitudinal (in which case the most recent prevalence data were used). Results from the analysis are presented in the forest plots in figure 2 .

\section{Pooled analysis by outcome}

Twenty studies were included in the pooled analysis of wasting. In 17 of the 20 studies, wasting was more prevalent in boys than girls, with evidence of a difference in $11 / 17$ of the studies. In the remaining three studies, wasting was more prevalent in girls than boys, with a significant difference in $1 / 3$ of the studies. The pooled results of individual studies for wasting showed that boys had 26\% higher odds of being wasted than girls (pooled OR $1.26,95 \%$ CI 1.13 to $1.40, \mathrm{p}<0.001$ ).

Thirty-eight studies were included in the pooled analysis of stunting. In 32 of the 38 studies, stunting was more prevalent in boys than girls, with evidence of a difference in 28/32 of the studies. In the remaining six studies, stunting was more prevalent in girls than boys, with a significant difference in $3 / 6$ of the studies. The pooled results for stunting showed that boys had 29\% higher odds of being stunted than girls (pooled OR $1.2995 \%$ CI 1.22 to $1.37, \mathrm{p}<0.001)$.

Twenty-three studies were included in the pooled analysis of underweight. In 18 of the 23 studies, underweight was more prevalent in boys than in girls, with evidence of a difference in $10 / 18$ of the studies. In the remaining five studies, girls were more likely to be underweight than boys, with a significant difference in $4 / 5$ of the studies. The pooled results for underweight showed that boys had $14 \%$ higher odds of being underweight than girls (OR $1.14,95 \%$ CI 1.02 to $1.26, \mathrm{p}<0.001)$.

\section{Pooled analysis by region}

When organised by region, the odds of boys being malnourished were nearly always higher than for girls for wasting, stunting and underweight. For wasting, the odds were higher for boys than for girls in all regions. For stunting, the odds were higher for boys than for girls in all regions except South Asia (pooled OR 0.88, 95\% CI 0.62 to $1.26, p=0.492$ ), where there was no difference by sex. For underweight, the odds were higher for boys than for girls in all regions except Central America (OR $0.53,95 \%$ CI 0.40 to $0.72, \mathrm{p}<0.001$ ), although this finding was from a single study, and South Asia (pooled OR 0.84, $95 \%$ CI 0.52 to $1.35, \mathrm{p}=0.475$ ). Results from the analysis are presented in table 2 . 

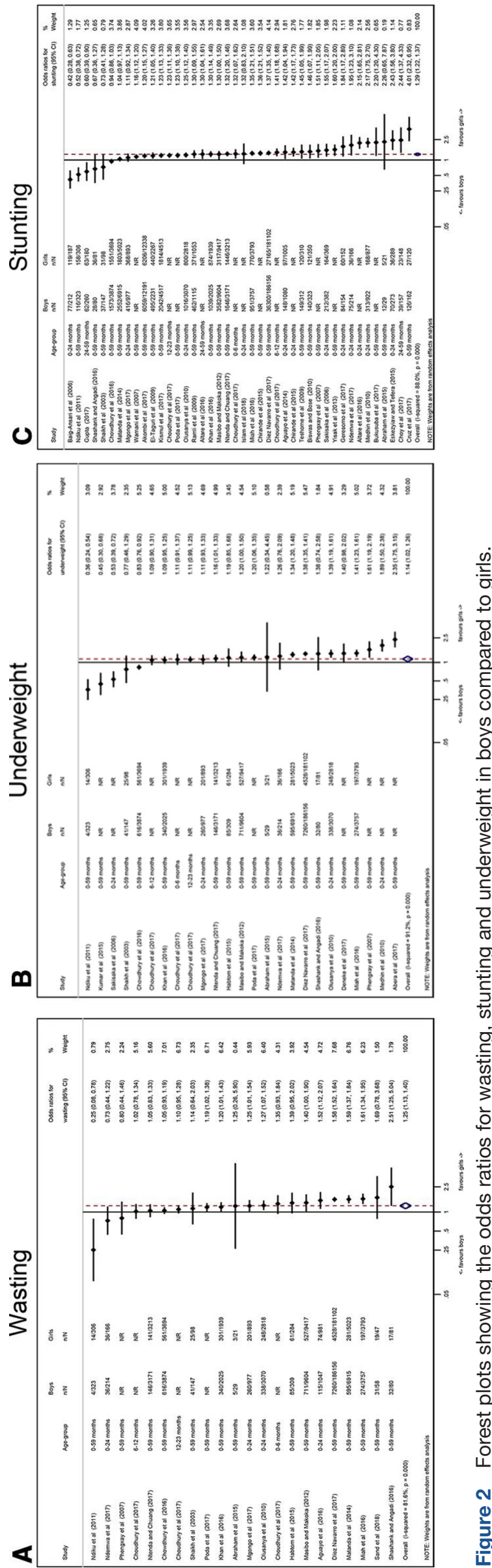

\section{Pooled analysis by age}

When organised by age groups, the odds of boys being wasted, stunted or underweight were higher in all age categories for boys than for girls. Results from the analysis are presented in table 2 .

We repeated the analysis for relative risk and found the results were consistent with results for ORs. There was strong evidence of between-study heterogeneity of effect, (wasting $\mathrm{I}^{2}=81.6 \%, \mathrm{p}<0.001$, stunting $\mathrm{I}^{2}=88.0 \%, \mathrm{p}<0.001$, underweight $\mathrm{I}^{2}=91.3 \%, \mathrm{p}<0.001$ ) which meta-regression by age group and region did not explain.

\section{Risk of bias within studies}

The quality assessment can be seen in table 3 . All studies presented appeared to be of acceptable quality. It is worth noting however that a number of studies were excluded prior to this process due to the absence of suitable data. The main differences in quality were in the domain which assessed whether sex differences were acknowledged and explored (see Qualitative synthesis section).

\section{Qualitative synthesis}

Seventy-four studies reported on outcomes related to undernutrition-wasting, stunting and underweight. From this, 38/74 studies reported on wasting as an outcome with $31 / 38(81 \%)$ reporting a higher prevalence of wasting in boys, $6 / 38(16 \%)$ reporting a higher prevalence of wasting in girls, $1 / 38(3 \%)$ reporting no difference in the prevalence of wasting between boys and girls. Sixty-seven of 74 studies reported on stunting as an outcome. Fifty-four of $67(81 \%)$ reported a higher prevalence of stunting in boys and 13/67 (19\%) reported higher prevalence of stunting in girls. Thirty-five of 74 studies reported on underweight as an outcome. Twentyeight of $35(80 \%)$ reported higher prevalence of being underweight in boys, $7 / 35$ (20\%) reported a higher prevalence of underweight in girls.

We reviewed the discussion sections of the reports to see if these findings were explicitly acknowledged and if explanations were offered. Forty-three of $74(58 \%)$ of the studies discussed the findings, 10/74 (14\%) studies cited articles with similar findings but did not speculate as to the causes of these differences and 21/74 (28\%) of the studies did not discuss the findings related to sex differences at all.

Among those study reports that did offer explanations for sex differences, the reasons varied widely and were often conjectural. We coded explanations as either biological $(6 / 43 ; 14 \%)$, social $(21 / 43 ; 49 \%)$ or a combination of the two $(16 / 43 ; 37 \%)$. Biological reasons varied from a simple statement of 'biological differences' to more detailed exploration of sex differences in the immune and endocrine system between boys and girls. Social reasons given varied widely and were almost entirely conjectural, with exceptions identified through regression analysis related to son preference and related to sibling order and sex. Other social reasons given were gender dynamics, preferential feeding practices 
Table 2 Odds of boys being undernourished compared with girls by regions and age groups

\begin{tabular}{|c|c|c|c|c|c|c|c|c|c|}
\hline Region/age groups & $\begin{array}{l}\text { No. of } \\
\text { studies of } \\
\text { wasting }\end{array}$ & $\begin{array}{l}\text { Pooled OR } \\
(95 \% \mathrm{Cl})\end{array}$ & $P$ value & $\begin{array}{l}\text { No. of } \\
\text { studies of } \\
\text { stunting }\end{array}$ & $\begin{array}{l}\text { Pooled OR } \\
(95 \% \mathrm{Cl})\end{array}$ & $P$ value & $\begin{array}{l}\text { No. of } \\
\text { studies of } \\
\text { underweight }\end{array}$ & $\begin{array}{l}\text { Pooled OR } \\
(95 \% \mathrm{Cl})\end{array}$ & $P$ value \\
\hline \multicolumn{10}{|l|}{ Africa } \\
\hline East & 8 & $\begin{array}{l}1.18 \\
\text { (0.95 to } 1.47)\end{array}$ & 0.126 & 17 & $\begin{array}{l}1.50 \\
(1.29 \text { to } 1.72)\end{array}$ & $<0.001$ & 11 & $\begin{array}{l}1.24 \\
(1.02 \text { to } 1.50)\end{array}$ & $<0.0034$ \\
\hline West & 3 & $\begin{array}{l}1.34 \\
\text { (1.12 to } 1.59)\end{array}$ & 0.001 & 4 & $\begin{array}{l}1.24 \\
\text { (1.18 to } 1.30)\end{array}$ & $<0.001$ & 3 & $\begin{array}{l}1.32 \\
\text { (1.19 to } 1.47)\end{array}$ & $<0.001$ \\
\hline Central & & & & 1 & $\begin{array}{l}1.23 \\
\text { (1.13 to } 1.33)\end{array}$ & $<0.001$ & & & \\
\hline North & & & & 1 & $\begin{array}{l}1.21 \\
\text { (1.05 to } 1.40)\end{array}$ & 0.009 & & & \\
\hline Oceania & & & & 1 & $\begin{array}{l}2.44 \\
\text { (1.37 to } 4.33)\end{array}$ & 0.002 & & & \\
\hline \multicolumn{10}{|l|}{ Asia } \\
\hline South & 5 & $\begin{array}{l}1.39 \\
\text { (1.12 to } 1.72)\end{array}$ & 0.003 & 7 & $\begin{array}{l}0.88 \\
\text { (0.62 to } 1.26)\end{array}$ & 0.492 & 4 & $\begin{array}{l}0.84 \\
(0.52 \text { to } 1.35)\end{array}$ & 0.475 \\
\hline South East & 3 & $\begin{array}{l}1.08 \\
\text { (0.99 to } 1.17)\end{array}$ & 0.092 & 5 & $\begin{array}{l}1.25 \\
(1.08 \text { to } 1.45)\end{array}$ & 0.003 & 3 & $\begin{array}{l}1.09 \\
\text { (0.91 to } 1.32)\end{array}$ & 0.350 \\
\hline Central America & & & & 1 & $\begin{array}{l}1.56 \\
\text { (1.17 to } 2.07)\end{array}$ & 0.003 & 1 & $\begin{array}{l}0.53 \\
(0.40 \text { to } 0.72)\end{array}$ & $<0.001$ \\
\hline Multiple studies & 1 & $\begin{array}{l}1.58 \\
\text { (1.52 to } 1.64)\end{array}$ & $<0.001$ & 2 & $\begin{array}{l}1.26 \\
(1.07 \text { to } 1.49)\end{array}$ & 0.006 & 1 & $\begin{array}{l}1.38 \\
\text { (1.35 to } 1.41)\end{array}$ & $<0.001$ \\
\hline \multicolumn{10}{|l|}{ Age group (months) } \\
\hline $0-24$ & 5 & $\begin{array}{l}1.19 \\
(1.06 \text { to } 1.34)\end{array}$ & 0.004 & 12 & $\begin{array}{l}1.46 \\
(1.20 \text { to } 1.79)\end{array}$ & $<0.001$ & 5 & $\begin{array}{l}1.15 \\
(0.80 \text { to } 1.65)\end{array}$ & 0.445 \\
\hline $24-59$ & & & & 3 & $\begin{array}{l}1.21 \\
\text { (0.63 to } 2.33)\end{array}$ & 0.572 & & & \\
\hline $0-59$ & 15 & $\begin{array}{l}1.30 \\
(1.13 \text { to } 1.48)\end{array}$ & $<0.001$ & 24 & $\begin{array}{l}1.24 \\
\text { (1.16 to } 1.32)\end{array}$ & $<0.001$ & 17 & $\begin{array}{l}1.13 \\
\text { (0.99 to } 1.29)\end{array}$ & 0.066 \\
\hline
\end{tabular}

for either boys or girls, infant and young child feeding practices such as early weaning for boys and children's behaviours whereby girls might stay closer to the home and have more access to food being cooked, while boys play outside and in turn eat less while expending more energy.

\section{DISCUSSION}

This review offers a systematic look at sex differences over a wide geographical area. The studies included in the meta-analysis show that boys aged 0-59 months are much more likely to be wasted, stunted and underweight using anthropometric case definitions than girls. This indicates sex differences in susceptibility to undernutrition. The reasons currently provided for these differences vary and are often speculative rather than informed by direct evidence.

When stratified by region, the results also showed that boys are more likely to be wasted, stunted or underweight than girls. There were however some exceptions where ORs were reduced or reversed for boys with respect to undernutrition, in East Africa, Central America, South and South East Asia. The differences in Central America were based solely on one study, with a limited sample size and therefore need to be interpreted with caution. Our analysis potentially masks some of the complexities of regional variations in sex differences, particularly in South and South East Asia as many studies from these regions did not qualify for inclusion in the meta-analysis due to insufficient data. It is possible these differences might be under or overestimated. In reviewing the individual studies identified in the main search, results from this region are inconsistent and often conflicting compared with those coming from other regions of the world, such as Africa, which show a more consistent pattern of male disadvantage, a finding resonating with other studies. ${ }^{521}$ The inconsistencies in findings for parts of South and South East Asia, however, may be explained in part by well-described social preferences for men, ${ }^{22}$ and warrant further investigation. Such differences have also been described for under-5 mortality, with excess female child mortality for certain diseases, and according to socioeconomic status, birth order and family composition. ${ }^{23-26}$

These findings challenge commonly held assumptions within the nutrition community that girls are more likely to be affected by undernutrition. Recent studies focused on the relationship between wasting and stunting have also highlighted similar findings showing boys are more likely to be concurrently wasted and stunted than girls $^{427-29}$ and have identified this as an unexpected finding.

We found that even where sex differences are reported, they are not always acknowledged or explored. Just over a quarter of studies (28\%) did not provide any discussion 


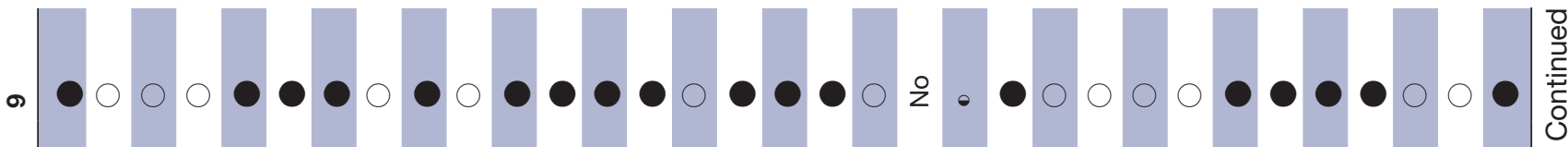

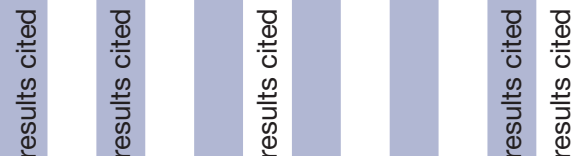

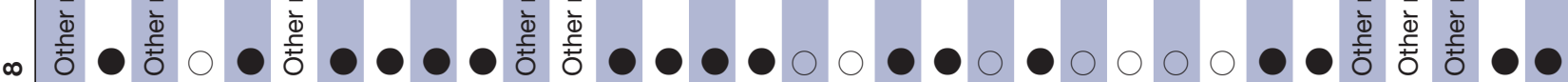

^ 000000000000000000000000.00000000 ᄂ 0.00000000000000 .0000000000000000 - 00000000000000000000000000000000 ๓ 00000000000000000000000000000000 n - 00000000000000000000000000000000

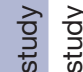

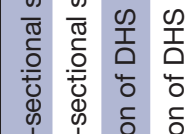

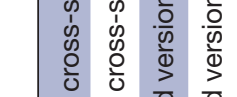

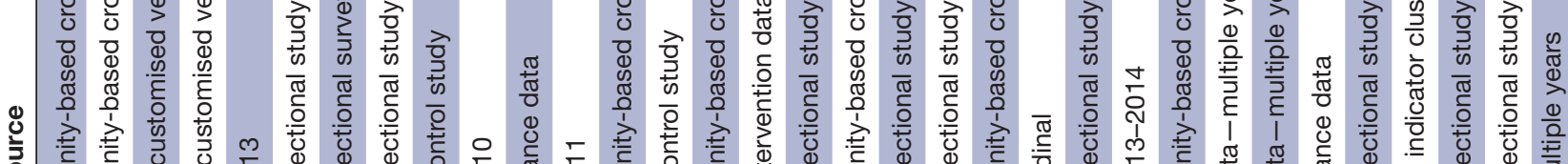

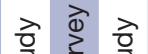

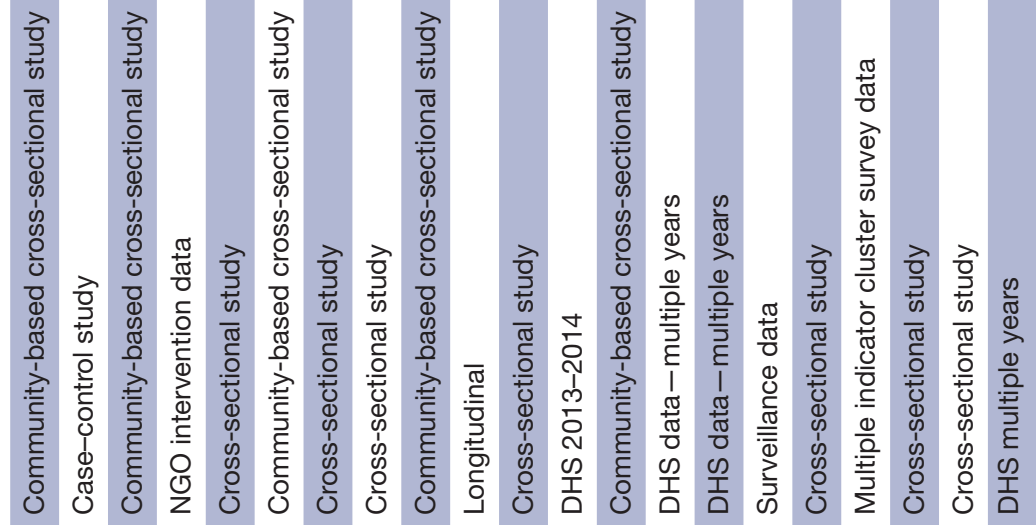

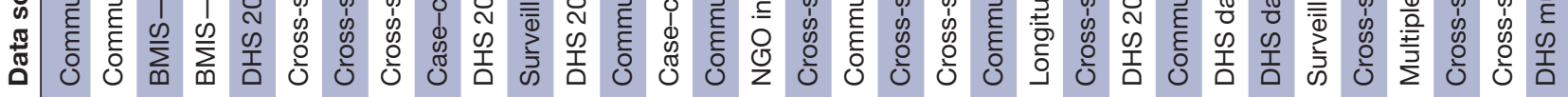




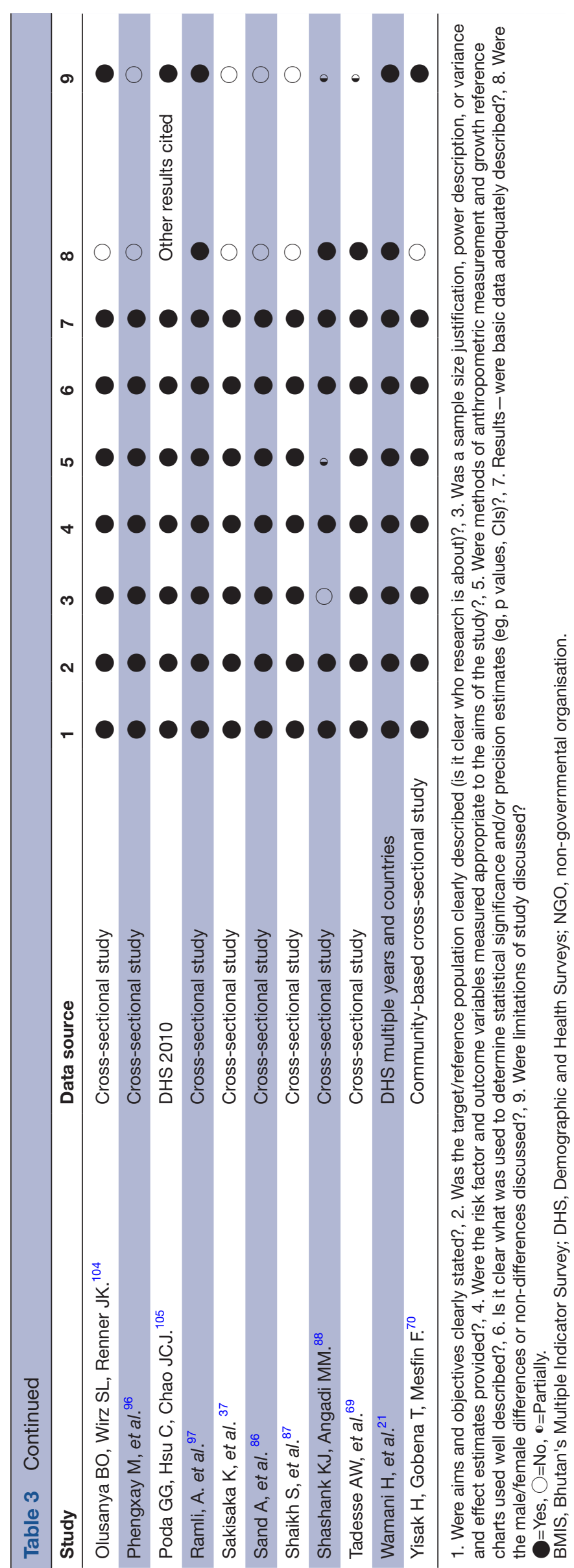

on reported differences and $14 \%$ cited similar findings but did not consider causes. Where explanations for sex differences in the prevalence of undernutrition were offered, nearly half $(49 \%)$ of the studies reviewed offered explanations related to social reasons or based on speculation or preconceived supposition rather than evidence. The search criteria used (which filtered articles to those which use terms related to sex or gender in the abstract) might have introduced some bias here with a potential overestimation of studies that report and explore the issue of sex differences.

When stratified by age, the meta-analysis also shows that boys are at higher risk across all age groups, though again, our analysis potentially masks some of the complexities in age as detailed analysis of different age groups was not possible. While the results for age show that boys are more likely to be stunted than girls, the ORs are lower in the older age group compared with the younger group. Limited data in the 24-59 month age category, especially for wasting and underweight, however mean results must be interpreted with caution. These tentative results might indicate any sex-specific risks differ at different ages: further study is warranted. Two studies exploring concurrent wasting and stunting ${ }^{28}{ }^{29}$ found it to be a condition that affects children below 30 months more than it does older children, and found that sex ratios in undernourished children change with age, with a higher susceptibility for boys up to 30 months that then disappeared. Alongside other studies,${ }^{30}$ they suggest that sex hormones, specifically testosterone, luteinising hormone and follicle-stimulating hormones might play a role in this. Selection effects might also contribute to this, whereby if boys are more likely to die than girls, the remaining pool of boys would represent healthy survivors.

Adair and Guilkey ${ }^{31}$ studied children in the Philippines and found men were more likely to become stunted in the first year of life (using the NCHS reference), but women were more likely than men to become stunted in the second year. They suggest differences in parental caregiving behaviours may partly account for this finding, but these were not measured in the study. Bork and Diallo $^{32}$ also found evidence of interaction between age and sex in that the deficit in boys compared with that in girls increased between the first and second years of life, regardless of the indicator used. The differences in height status were however sensitive to the growth reference chosen; they were greater when assessed using the 2006 WHO growth standards than when using the NCHS growth reference.

Sex differences in undernutrition may vary not only by geographical area, but also over time. When diseases causing undernutrition known to be more severe among girls, such as measles, whooping cough and tuberculosis, disappear because of vaccination, lower transmission and better feeding, the disadvantage of boys might increase. Conversely, if efficient nutrition programmes are conducted, the disadvantage of boys might be reduced over the years. 
Interpretation of these findings into implications for practice and policy is limited at this stage but does warrant consideration and some degree of change. As a minimum, the systematic collection and reporting of disaggregated data by age and sex should be included in the design of programmes and assessments in all settings. Where differences are observed, particularly in programme admissions, these should be interpreted in light of sex differences in population burden in order to draw conclusions as to whether programmes are proving equally accessible to boys and girls, and then the potential causes of these differences should be considered and/or investigated. At present, boys' vulnerability to undernutrition is rarely a consideration in the design of nutrition programming, nor the formulation of policy. Moreover, some high-level international nutrition policies explicitly focus on the vulnerability of women and girls (eg, The Scaling Up Nutrition Movement Road Map for 2016-2020 Khara et $a l^{28}$ ). Similarly, the recent Inter-Agency Standing Committee guidance on gender in humanitarian action ${ }^{33}$ recognises the inequity in food intake that may be faced by women and girls in crises but makes no reference to higher levels of undernutrition among boys. The absence of any reflection on gender, or the misuse of the term to highlight solely the health of women and girls, is likely to unintentionally reinforce inequalities in health. ${ }^{7}$ In the Nutrition for Growth 2020 summit (https://nutritionforgrowth.org/) and beyond, a major focus will be on inequities in undernutrition and how they affect different groups in different locations. The emerging findings from this review have significance in ensuring consideration of these sex differences through an equity lens.

\section{Strengths and limitations}

One of the strengths of this study lies in the systematic approach that was chosen and its primary objective to review sex differences in undernutrition over a wide geographical area. However, there are areas where bias has potentially been introduced.

First, screening for studies to be included in this study was conducted by only one of the authors. While we employed systems to ensure contentious articles were discussed among two or more authors, we recognise that not using double screening is a limitation. ${ }^{34}$

Second, the search strategy looking for explicit mention of sex or gender in the abstract might have biased towards studies that reported on sex and gender in the abstract, or towards studies that found a significant difference, and therefore sex differences might be under-reported or over-reported in this study. Likewise, the search may have limited the analysis as there are potentially missed studies which include sex as a variable in analysis but without focusing on mention of sex in the study abstracts. Similarly, there may be a degree of publication bias whereby sex differences are simply not considered or reported.
The search criteria also encompassed a large number of studies with differing objectives meaning a limited degree of homogeneity. Few studies directly assessed the true relation between sex and undernutrition. This analysis is therefore potentially biased by healthy survivors-those children that have survived to be included in studies. We do not believe however that our results would be significantly different considering the evidence presented on male vulnerability. We also recognise the possibility of an overlap in data used from sources such as Demographic and Health Surveys (DHS). By comparing the dates and locations of included studies, we have not been able to establish any overlap. Unidentified overlap, if it occurs, is therefore likely to be minimal in our review and unlikely to affect overall conclusions. Where multiple studies are available from the same country, we have established these to be from different regions and times, therefore their inclusion as independent studies is justified. We hope that our review will stimulate future work to explore not just intercountry differences but also intracountry/regional differences as this would help understand biological versus social reasons for any difference in male/female risks.

While this analysis included some secondary DHS data, the subject in question could benefit from a systematic analysis of DHS, Multiple Indicator Cluster Surveys and or nutrition survey data. Though it is not believed that the outcome of the ORs of sex differences would be different, further analysis might help improve understanding of some of the complexities of age, context, dual burdens of undernutrition and sex differences and the implications for programmers. This might also help towards explaining some of the between-study heterogeneity that we identified but were unable to explain with our analysis.

The rigour of findings of the analysis is limited in relation to age as the grouping and degree of available data potentially masks some of the differences at various stages of the lifecycle, similarly geographical differences might be biased towards studies included through the search.

The absence of data on other anthropometric measures, such as Mid-Upper Arm Circumference (MUAC), is also a potential limitation. In considering the implications of the differences highlighted here, in addition to biological and social explanations, it is necessary to consider how we measure and define undernutrition and whether sex differences are an artefact of the indices in use. The WHO growth standards describe the physiological growth within optimal environmental conditions and are separated by sex. These reference data from healthy well-nourished populations resolve sex differences to zero by expressing data as z-scores calculated using the appropriate male and female subset of the reference population. However, it is unclear if we would expect sex differences in undernutrition expressed in this way to be zero, when the distribution of weight and height in both sexes has been shifted away from the healthy reference range. Likewise, it is unclear if the loss of the same 
amount of body weight in a girl or boy would have the same physiological effect. If boys cope worse than girls when exposed to food shortages or disease and infection, this potentially highlights increased vulnerability over and above what is already accounted for by the standards.

In comparison, MUAC cut-offs are unadjusted and do not differentiate by sex or age (between 6 months and 5 years). This absence of adjustment may lead to a preferential inclusion of girls in programmes compared with what would be obtained if sex-specific standards were used as girls tend to have lower MUACs than boys. Though it has been shown to be a good predictor of mortality, sex differences in using MUAC to define undernutrition have not been widely studied.

Finally, the number of studies identified in the overall search that qualified for the meta-analysis was low. This was mainly due to a lack of presentation of disaggregated data. A recent Lancet series on gender equality, norms and health, highlighted the need for accurate disaggregated data. ${ }^{35}$

\section{Implications for future research}

This study is a step towards better understanding of sex differences in undernutrition and highlights the need to consider potential implications for policy and practice. Future research should aim to unpack the complexities related to age, biological and social risks (including gender norms) and context. In particular, we note that current papers are conjectural about reasons for observed differences. Any hypotheses should be more directly tested in future studies to further our understanding of sex differences in the context of undernutrition and subregional variations in order to determine the implications of these differences for programme staff and policymakers.

Future research will focus on a more detailed analysis of factors affecting outcomes for boys and girls such as epidemiological, demographic and social differences, explore the consequences of sex, age, and behavioural differences in nutritional outcomes and mortality. The impact of using differing anthropometric measurement and indices should also be explored to better understand how differing methods detect the most vulnerable children and explore how substantial sex differences are.

\section{CONCLUSION}

This review demonstrates that undernutrition defined by anthropometric case definitions is usually higher among boys than girls. While further research is needed to understand the policy and programming implications of these differences, lessons can already be drawn from this research. We call on nutrition actors to improve data collection in programmes, surveys and research through the full disaggregation and analysis of sex and age in order to identify which children are most vulnerable in specific contexts, and to allow comparison of programme data with population-level burdens. It is important to understand that the message of this study is not that boys should be prioritised over girls, rather it seeks to support all at-risk children, through improved understanding of sex differences in undernutrition. Ultimately, we believe all children under 5 years and their caregivers should be seen as a high priority group for targeted nutrition interventions, and resources and interventions should be targeted according to need.

\section{Author affiliations}

${ }^{1}$ Department of Population Health, London School of Hygiene and Tropical Medicine, London, UK

${ }^{2}$ Department of Medical Statistics, Faculty of Epidemiology and Population Health, London School of Hygiene and Tropical Medicine, London, UK

${ }^{3}$ National Perinatal Epidemiology Unit, Nuffield Department of Population Health,

University of Oxford, Oxford, UK

${ }^{4}$ Institute for Global Health, University College London, London, UK

${ }^{5}$ Great Ormond Street Institute of Child Health, University College London, London, UK

${ }^{6}$ Emergency Nutrition Network, Kidlington, UK

${ }^{7}$ Department of Nutrition, Exercise and Sports, University of Copenhagen, Kobenhavn, Denmark

${ }^{8}$ School of Medicine, Center for Child Health Research,

${ }^{9}$ Brixton Health, Llwyngwril, Gwynedd, UK

${ }^{10}$ Institut de Recherche pour le Développement, UMI Résiliences, Bondy, France

${ }^{11}$ Institut Pasteur, Epidémiologie des Maladies Emergentes, Paris, France

${ }^{12}$ FERDI, Université d'Auvergne, Clermont-Ferrand, France

${ }^{13} \mathrm{MRC} /$ Wits Rural Public Health and Health Transitions Research Unit, School of Public Health, Faculty of Health Sciences, University of the Witwatersrand, Johannesburg, South Africa

${ }^{14}$ Centre for MARCH (Maternal, Adolescent \& Reproductive Child Health), London School of Hygiene and Tropical Medicine, London, UK

Twitter Charles 0pondo @charlesopondo and Marko Kerac @GlobalHealthNut

Acknowledgements We would like to acknowledge and thank Zoe Thomas at the London School of Hygiene and Tropical Medicine Library for her review of the search terms used in this study.

Contributors The review was designed and conducted by ST with supervision from MK and RS. The meta-analysis was led by ST supported by CO. ST led the writing of the manuscript for publication with contributions from all authors.

Funding This paper is made possible by funding from Irish Aid (grant number HQPU/2020/ENN) and the generous support of the American people through the United States Agency for International Development (USAID).

Competing interests None declared.

Patient consent for publication Not required.

Provenance and peer review Not commissioned; externally peer reviewed.

Data availability statement Data used were from published studies available in a public, open access repository. The datasets generated for the current study are available from the corresponding author on reasonable request.

Supplemental material This content has been supplied by the author(s). It has not been vetted by BMJ Publishing Group Limited (BMJ) and may not have been peer-reviewed. Any opinions or recommendations discussed are solely those of the author(s) and are not endorsed by BMJ. BMJ disclaims all liability and responsibility arising from any reliance placed on the content. Where the content includes any translated material, BMJ does not warrant the accuracy and reliability of the translations (including but not limited to local regulations, clinical guidelines, terminology, drug names and drug dosages), and is not responsible for any error and/or omissions arising from translation and adaptation or otherwise.

Open access This is an open access article distributed in accordance with the Creative Commons Attribution 4.0 Unported (CC BY 4.0) license, which permits others to copy, redistribute, remix, transform and build upon this work for any purpose, provided the original work is properly cited, a link to the licence is given, and indication of whether changes were made. See: https://creativecommons.org/ licenses/by/4.0/. 


\section{ORCID iDs}

Susan Thurstans http://orcid.org/0000-0002-7102-446X Charles Opondo http://orcid.org/0000-0001-8155-4117 Andrew Seal http://orcid.org/0000-0003-3656-4054 Jonathan Wells http://orcid.org/0000-0003-0411-8025 Michel Garenne http://orcid.org/0000-0001-6073-7803 Rebecca Sear http://orcid.org/0000-0002-4315-0223 Marko Kerac http://orcid.org/0000-0002-3745-7317

\section{REFERENCES}

1 UNICEF/WHO/The World Bank Group. Joint child malnutrition estimates: levels and trends in child malnutrition, 2019.

2 Isanaka S, Boundy Ellen O'Neal, Grais RF, et al. Improving estimates of numbers of children with severe acute malnutrition using cohort and survey data. Am J Epidemiol 2016;184:861-9.

3 Heidari S, Babor TF, De Castro P, et al. Sex and gender equity in research: rationale for the SAGER guidelines and recommended use. Res Integr Peer Rev 2016;1:2.

4 Wells JC. Natural selection and sex differences in morbidity and mortality in early life. J Theor Biol 2000;202:65-76.

5 Garenne M. Sex differences in health indicators among children in African DHS surveys. J Biosoc Sci 2003;35:601-14.

6 Kraemer S. The fragile male. BMJ 2000;321:1609-12.

7 Hawkes S, Buse K. Gender and global health: evidence, policy, and inconvenient truths. Lancet 2013;381:1783-7.

8 Garenne M, Lafon M. Sexist diseases. Perspect Biol Med 1998;41:176-90.

9 WHO. WHO guideline on health policy and system support to optimize community health worker programmes, 2018.

10 FAO. Gender and nutrition, 2020.

11 Oniang'O R, Mukudi E. Nutrition and gender, 2001

12 Institute IFPR. Global hunger index: the inequalities of hunger, 2017.

13 UNICEF. UNICEF gender action plan, 2017: 2018-21.

14 Hamill PV, Drizd TA, Johnson CL, et al. Physical growth: national center for health statistics percentiles. Am J Clin Nutr 1979;32:607-29.

15 WHO. WHO child growth standards. growth velocity based on weight, length and head circumference methods and development, 2006.

16 Andersen GS, Girma T, Wells JCK, et al. Body composition from birth to $6 \mathrm{Mo}$ of age in Ethiopian infants: reference data obtained by air-displacement plethysmography. Am J Clin Nutr 2013;98:885-94.

17 Wells JCK, Davies PSW, Fewtrell MS, et al. Body composition reference charts for UK infants and children aged 6 weeks to 5 years based on measurement of total body water by isotope dilution. Eur J Clin Nutr 2020;74:141-8.

18 Moher D, Liberati A, Tetzlaff J, et al. Preferred reporting items for systematic reviews and meta-analyses: the PRISMA statement. BMJ 2009;339:b2535.

19 Hamill PV, Drizd TA, Johnson CL, et al. NCHS growth curves for children birth-18 years. United States. Vital Health Stat 11 1977:165:1-74.

20 NHLBI. Quality assessment tool for observational cohort and crosssectional studies, 2018.

21 Wamani H, Astrøm AN, Peterson S, et al. Boys are more stunted than girls in sub-Saharan Africa: a meta-analysis of 16 demographic and health surveys. BMC Pediatr 2007;7:17.

22 Khera R, Jain S, Lodha R, et al. Gender bias in child care and child health: global patterns. Arch Dis Child 2014;99:369-74.

23 Gupta MD. Selective discrimination against female children in rural Punjab, India. Popul Dev Rev 1987;13:77-100.

24 Das Gupta M, Clustering D. Death clustering, mothers' education and the determinants of child mortality in rural Punjab, India. Popul Stud 1990;44:489-505.

25 Kuntla S, Goli S, Jain K. Explaining sex differentials in child mortality in India: trends and determinants. Int J Popul Res 2014;2014:1-7

26 Wyon JB, Gordon JE. Khanna study, 2014

27 Díez-Navarro Aet al. Female eco-stability and severe malnutrition in children: evidence from humanitarian aid interventions of action against hunger in African, Asian and Latin American countries. Nutricion Clinica y Dietetica Hospitalaria 2017;34:127-34.

28 Khara T, Mwangome M, Ngari M, et al. Children concurrently wasted and stunted: A meta-analysis of prevalence data of children 6-59 months from 84 countries. Matern Child Nutr 2018;14:e12516.

29 Myatt M, Khara T, Schoenbuchner S, et al. Children who are both wasted and stunted are also underweight and have a high risk of death: a descriptive epidemiology of multiple anthropometric deficits using data from 51 countries. Arch Public Health 2018;76:28.

30 Schoenbuchner SM, Dolan C, Mwangome M, et al. The relationship between wasting and stunting: a retrospective cohort analysis of longitudinal data in Gambian children from 1976 to 2016. Am J Clin Nutr 2019:110:498-507.

31 Adair LS, Guilkey DK. Age-specific determinants of stunting in Filipino children. J Nutr 1997;127:314-20.

32 Bork KA, Diallo A. Boys are more stunted than girls from early infancy to 3 years of age in rural Senegal. J Nutr 2017;147:940-7.

33 IASC. The gender handbook for humanitarian action, 2017.

34 Gartlehner G, Affengruber L, Titscher V, et al. Single-reviewer abstract screening missed 13 percent of relevant studies: a crowd-based, randomized controlled trial. J Clin Epidemiol 2020;121:20-8.

35 Gupta GR, Oomman N, Grown C, et al. Gender equality and gender norms: framing the opportunities for health. Lancet 2019;393:2550-62

36 Kismul H, Acharya P, Mapatano MA, et al. Determinants of childhood stunting in the Democratic Republic of Congo: further analysis of demographic and health survey 2013-14. BMC Public Health 2018;18:74.

37 Sakisaka K, Wakai S, Kuroiwa C, et al. Nutritional status and associated factors in children aged 0-23 months in Granada, Nicaragua. Public Health 2006;120:400-11.

38 Kismul H, Acharya P, Mapatano MA, et al. Determinants of childhood stunting in the Democratic Republic of Congo: further analysis of demographic and health survey 2013-14. BMC Public Health 2017; 18:74.

39 Abdulahi A, Shab-Bidar S, Rezaei S, et al. Nutritional status of under five children in Ethiopia: a systematic review and metaanalysis. Ethiop J Health Sci 2017;27:175.

40 Abera L, Dejene T, Laelago T. Prevalence of malnutrition and associated factors in children aged 6-59 months among rural dwellers of damot gale district, south Ethiopia: community based cross sectional study. Int J Equity Health 2017;16:111.

41 Degarege A, Hailemeskel E, Erko B. Age-Related factors influencing the occurrence of undernutrition in northeastern Ethiopia. BMC Public Health 2015;15:108

42 Altare C, Delbiso TD, Mutwiri GM, et al. Factors associated with stunting among pre-school children in southern highlands of Tanzania. J Trop Pediatr 2016;62:390-408.

43 Asfaw M, Wondaferash M, Taha M, et al. Prevalence of undernutrition and associated factors among children aged between six to fifty nine months in Bule HorA district, South Ethiopia. BMC Public Health 2015;15:41.

44 Bukusuba J, Kaaya AN, Atukwase A. Predictors of stunting in children aged 6 to 59 months: a case-control study in Southwest Uganda. Food Nutr Bull 2017;38:542-53.

45 Chirande L, Charwe D, Mbwana H, et al. Determinants of stunting and severe stunting among under-fives in Tanzania: evidence from the 2010 cross-sectional household survey. BMC Pediatr 2015; $15: 165$.

46 chirwa ephraimw, ngalawa haroldpe, Chirwa EW, Ngalawa HPE. Determinants of child nutrition in Malawi. South African Journal of Economics 2008;76:628-40.

47 Condo JU, Gage A, Mock N, Condo J, et al, et al. Sex differences in nutritional status of HIV-exposed children in Rwanda: a longitudinal study. Trop Med Int Health 2015;20:17-23.

48 Cruz LMG, Azpeitia GG, Súarez DR, et al. Factors associated with stunting among children aged 0 to 59 months from the central region of Mozambique. Nutrients 2017;9. doi:10.3390/nu9050491. [Epub ahead of print: 12 May 2017].

49 Tosheno D, Mehretie Adinew Y, Thangavel T, et al. Risk factors of underweight in children aged 6-59 months in Ethiopia. J Nutr Metab 2017;2017:1-8.

50 Agedew Eet al. Predictors of chronic under nutrition (stunting) among children aged 6-23 months in Kemba Woreda, southern Ethiopia: a community based cross-sectional study. J Nutr Food Sci 2015;05:4

51 Espo M, Kulmala T, Maleta K, et al. Determinants of linear growth and predictors of severe stunting during infancy in rural Malawi. Acta Paediatr 2002;91:1364-70.

52 Ettyang GA, Sawe CJ. Factors associated with stunting in children under age 2 in the Cambodia and Kenya 2014 demographic and health surveys. Rockville, Maryland: ICF international, 2016. https:// dhsprogram.com/pubs/pdf/WP126/WP126.pdf

53 Fentahun N, Belachew T, Lachat C. Determinants and morbidities of multiple anthropometric deficits in Southwest rural Ethiopia. Nutrition 2016;32:1243-9. 
54 Geresomo N, Mbuthia EK, Matofari JW, et al. Risk factors associated with stunting among infants and young children aged 6 - 23 months in Dedza district of central Malawi. African Journal Of Food, Agriculture, Nutrition And Development 2017;17:12854-70.

55 Gewa CA, Yandell N. Undernutrition among Kenyan children: contribution of child, maternal and household factors. Public Health Nutr 2012;15:1029-38

56 Medhin G, Hanlon C, Dewey M, et al. Prevalence and predictors of undernutrition among infants aged six and twelve months in Butajira, Ethiopia: the P-MaMiE birth cohort. BMC Public Health 2010;10:27.

57 Kelati H, Mengiste B, Alemayehu T, et al. Prevalence of Acute Malnutrition and its Associated Factors amongChildren aged 6-59 months in Mai-Aini Eritrean Refugees' Camp,Northern Ethiopia. Journal of Nutrition and Food Sciences 2015;5:1. doi:10.4172/2155-9600.1000336

58 Haile D, Azage M, Mola T, et al. Exploring spatial variations and factors associated with childhood stunting in Ethiopia: spatial and multilevel analysis. BMC Pediatr 2016;16:49.

59 Kinyoki DK, Kandala N-B, Manda SO, et al. Assessing comorbidity and correlates of wasting and stunting among children in Somalia using cross-sectional household surveys: 2007 to 2010. BMJ Open 2016;6:e009854.

60 Masibo PK, Makoka D. Trends and determinants of undernutrition among young Kenyan children: Kenya demographic and health survey; 1993, 1998, 2003 and 2008-2009. Public Health Nutr 2012;15:1715-27.

61 Matanda DJ, Mittelmark MB, Kigaru DMD. Child undernutrition in Kenya: trend analyses from 1993 to 2008-09. BMC Pediatr 2014; $14: 5$.

62 Mgongo M, Chotta NAS, Hashim TH, et al. Underweight, stunting and wasting among children in Kilimanjaro region, Tanzania; a population-based cross-sectional study. Int J Environ Res Public Health 2017;14. doi:10.3390/ijerph14050509. [Epub ahead of print: 1005 2017].

63 Moges Bet al. Magnitude of stunting and associated factors among 6-59 months old children in Hossana town, southern Ethiopia. Journal of Clinical Research and Bioethics 2015;6. doi:10.3390/ ijerph14050509

64 Ndemwa M, Wanyua S, Kaneko S, et al. Nutritional status and association of demographic characteristics with malnutrition among children less than 24 months in Kwale County, Kenya. Pan Afr Med J 2017;28:265.

65 Ndiku M, Jaceldo-Siegl K, Singh P, et al. Gender inequality in food intake and nutritional status of children under 5 years old in rural eastern Kenya. Eur J Clin Nutr 2011;65:26-31.

66 Ntenda PAM, Chuang Y-C. Analysis of individual-level and community-level effects on childhood undernutrition in Malawi. Pediatr Neonatol 2018;59:380-9.

67 Olwedo MA, Mworozi E, Bachou $\mathrm{H}$, et al. Factors associated with malnutrition among children in internally displaced person's camps, Northern Uganda. Afr Health Sci 2008;8:244-96.

68 Rakotomanana H, Gates GE, Hildebrand D, et al. Determinants of stunting in children under 5 years in Madagascar. Matern Child Nutr 2017;13. doi:10.1111/mcn.12409. [Epub ahead of print: 2812 2016].

69 Tadesse AW, Tadesse E, Berhane Y, et al. Comparison of MidUpper arm circumference and Weight-for-Height to diagnose severe acute malnutrition: a study in southern Ethiopia. Nutrients 2017;9. doi:10.3390/nu9030267. [Epub ahead of print: 11 Mar 2017]

70 Yisak H, Gobena T, Mesfin F. Prevalence and risk factors for under nutrition among children under five at Haramaya district, eastern Ethiopia. BMC Pediatr 2015;15:212.

71 Yourkavitch J. Trends and inequalities in young child nutrition in Rwanda: further analysis of the 2014-15 demographic and health survey, 2018. Available: https://dhsprogram.com/pubs/pdf/FA109/ FA109.pdf

72 Jiang Y, Su X, Wang C, et al. Prevalence and risk factors for stunting and severe stunting among children under three years old in mid-western rural areas of China. Child Care Health Dev 2015;41:45-51

73 Díez-Navarro A, et al. Female eco-stability and severe malnutrition in children: evidence from humanitarian aid interventions of action against hunger in African, Asian and Latin American countries. Nutricion Clinica y Dietetica Hospitalaria 2017;34:127-34.

74 Keino S, Plasqui G, Ettyang G, et al. Determinants of stunting and overweight among young children and adolescents in sub-Saharan Africa. Food Nutr Bull 2014;35:167-78.

75 El Taguri A, Betilmal I, Mahmud SM, et al. Risk factors for stunting among under-fives in Libya. Public Health Nutr 2009;12:1141-9.
76 Choy CC, Desai MM, Park JJ, et al. Child, maternal and householdlevel correlates of nutritional status: a cross-sectional study among young Samoan children. Public Health Nutr 2017;20:1235-47.

77 Castro BA, González ER, Álvarez MC, et al. Factors associated with stunted growth in children below 11 years of age in Antioquia, Colombia, 2004. Colomb Med 2011;42:204-14. doi:10.25100/ cm.v42i2.772

78 Correia LL, Silva ACe, Campos JS, et al. Prevalence and determinants of child undernutrition and stunting in semiarid region of Brazil. Rev Saude Publica 2014;48:19-28.

79 Aguayo VM, Badgaiyan N, Paintal K. Determinants of child stunting in the Royal Kingdom of Bhutan: an in-depth analysis of nationally representative data. Matern Child Nutr 2015;11:333-78.

80 Aguayo VM, Badgaiyan N, Dzed L. Determinants of child wasting in Bhutan. insights from nationally representative data. Public Health Nutr 2017;20:315-24.

81 Baig-Ansari N, Rahbar MH, Bhutta ZA, et al. Child's gender and household food insecurity are associated with stunting among young Pakistani children residing in urban squatter settlements. Food Nutr Bull 2006;27:114-27.

82 Biswas S, Bose K. Sex differences in the effect of birth order and parents' educational status on stunting: a study on Bengalee preschool children from eastern India. Homo 2010;61:271-6.

83 Gupta A. Assessing stunting and predisposing factors among children. Asian Journal of Pharmaceutical and Clinical Research 2017;10:364-71.

84 Khan ATetal. Prevalence and associated factors of malnutrition among children under-five5 years in Sindh, Pakistan: a crosssectional study. Tropical Medicine and International Health 2016;22:317-8

85 Kumar D, et al. Socio-Demographic factors affecting the nutritional status of the under three children in Chandigarh, UT. Healthline, Journal of Indian Association of Preventive and Social Medicine 2015;6:46-52.

86 Sand A, Kumar R, Shaikh BT, et al. Determinants of severe acute malnutrition among children under five years in a rural remote setting: a hospital based study from district Tharparkar-Sindh, Pakistan. Pak J Med Sci 2018;34:260-5. doi:10.12669/pjms.342.14977

87 Shaikh S, Mahalanabis D, Chatterjee S, et al. Lean body mass in preschool aged urban children in India: gender difference. Eur $J$ Clin Nutr 2003;57:389-93.

88 Shashank KJ, Angadi MM. Gender disparity in health and nutritional status among under-five children in a rural field practice area of Shri BM Patil medical college. International Journal of Medical Science and Public Health 2016;5:217-20.

89 Adair LS, Guilkey DK. Age-Specific determinants of stunting in Filipino children. J Nutr 1997;127:314-20.

90 Ahmed AMS, Ahmed T, Roy SK, et al. Determinants of undernutrition in children under 2 years of age from rura Bangladesh. Indian Pediatr 2012;49:821-4.

91 Choudhury N, Raihan MJ, Sultana S, et al. Determinants of agespecific undernutrition in children aged less than 2 years-the Bangladesh context. Matern Child Nutr 2017;13. doi:10.1111/ mcn.12362. [Epub ahead of print: 1210 2016].

92 Chowdhury MRK, Rahman MS, Khan MMH, et al. Risk factors for child malnutrition in Bangladesh: a multilevel analysis of a nationwide population-based survey. $J$ Pediatr 2016;172:194-201.

93 Dancer D, Rammohan A, Smith MD. Infant mortality and child nutrition in Bangladesh. Health Econ 2008;17:1015-35.

94 Islam MM, Sanin KI, Mahfuz M, et al. Risk factors of stunting among children living in an urban slum of Bangladesh: findings of a prospective cohort study. BMC Public Health 2018;18:197.

95 Khambalia AZ, Lim SS, Gill T, et al. Prevalence and sociodemographic factors of malnutrition among children in Malaysia. Food Nutr Bull 2012;33:31-42.

96 Phengxay M, Ali M, Yagyu F, et al. Risk factors for protein-energy malnutrition in children under 5 years: study from Luangprabang Province, Laos. Pediatr Int 2007;49:260-5.

97 Ramli, Agho KE, Inder KJ, et al. Prevalence and risk factors for stunting and severe stunting among under-fives in North Maluku Province of Indonesia. BMC Pediatr 2009;9:64.

98 Olita'a D, Vince J, Ripa P, et al. Risk factors for malnutrition in children at Port Moresby General Hospital, Papua New Guinea: a case-control study. J Trop Pediatr 2014;60:442-8.

99 Akombi BJ, Agho KE, Hall JJ, et al. Stunting and severe stunting among children under-5 years in Nigeria: A multilevel analysis. BMC Pediatr 2017; 17:15

100 Amugsi DA, Mittelmark MB, Lartey A. An analysis of sociodemographic patterns in child malnutrition trends using Ghana 
demographic and health survey data in the period 1993-2008. BMC Public Health 2013;13:960.

101 Darteh EKM, Acquah E, Kumi-Kyereme A. Correlates of stunting among children in Ghana. BMC Public Health 2014;14:504. doi:10.1186/1471-2458-14-504

102 Garenne M, Myatt M, Khara T, et al. Concurrent wasting and stunting among under-five children in Niakhar, Senegal. Matern Child Nutr 2019;15:e12736.

103 Miah RW, Apanga PA, Abdul-Haq Z, et al. Risk factors for undernutrition in children under five 5 years old: evidence from the 2011 Ghana multiple indicator cluster survey. Journal of AIDS and Clinical Research 2016;7. doi:10.4172/2155-6113.1000585

104 Olusanya BO, Wirz SL, Renner JK, Prevalence RJK. Prevalence, pattern and risk factors for undernutrition in early infancy using the who multicentre growth reference: a community-based study. Paediatr Perinat Epidemiol 2010;24:572-83.

105 Fuchs C, Sultana T, Ahmed T, et al. Factors associated with acute malnutrition among children admitted to a diarrhoea treatment facility in Bangladesh. Int J Pediatr 2014;2014:1:5. doi:10.1155/2014/267806 